\title{
Can an hour or two of sun protection education keep the sunburn away? Evaluation of the Environmental Protection Agency's Sunwise School Program
}

\author{
Alan C Geller*1, Linda Rutsch², Kristin Kenausis², Paula Selzer ${ }^{2}$ and \\ Zi Zhang 3
}

Address: ${ }^{1}$ Department of Dermatology, Boston University School of Medicine, Boston Massachusetts, USA, ${ }^{2}$ Environmental Protection Agency, Washington DC, USA and ${ }^{3}$ Massachusetts Department of Public Health, Boston Massachusetts, USA

Email: Alan C Geller* - ageller@bu.edu; Linda Rutsch - rutsch.linda@epamail.gov; Kristin Kenausis - kenausis.kristin@epamail.gov; Paula Selzer - selzer.paula@epamail.gov; Zi Zhang - zi.zhang@state.ma.us

* Corresponding author

Published: 03 November 2003

Environmental Health: A Global Access Science Source 2003, 2:13

This article is available from: http://www.ehjournal.net/content/2/1//3

(C) 2003 Geller et al; licensee BioMed Central Ltd. This is an Open Access article: verbatim copying and redistribution of this article are permitted in all media for any purpose, provided this notice is preserved along with the article's original URL.
Received: 20 August 2003

Accepted: 03 November 2003

\begin{abstract}
Background: Melanoma incidence is rising at a rate faster than any other preventable cancer in the United States. Childhood exposure to ultraviolet (UV) light increases risk for skin cancer as an adult, thus starting positive sun protection habits early may be key to reducing the incidence of this disease.

Methods: The Environmental Protection Agency's SunWise School Program, a national environmental and health education program for sun safety of children in primary and secondary schools (grades K-8), was evaluated with surveys administered to participating students and faculty.

Results: Pretests $(n=5,625)$ and posttests $(n=5,028)$ were completed by students in 102 schools in 42 states. Significant improvement was noted for the three knowledge variables. Intentions to play in the shade increased from $68 \%$ to $75 \%(p<0.001)$ with more modest changes in intentions to use sunscreen. Attitudes regarding healthiness of a tan also decreased significantly.
\end{abstract}

Conclusions: Brief, standardized sun protection education can be efficiently interwoven into existing school curricula, and result in improvements in knowledge and positive intentions for sun protection.

\section{Background}

Skin cancer now comprises more than half of the 2.5 million cancers diagnosed in the United States [1]. The incidence rate for melanoma, the most fatal form of skin cancer, is growing at an alarming rate, accounting for the greatest increases in the last decade among all preventable cancers $[2,3]$. And yet, skin cancer is largely preventable by public education and behavior change [4]. Moreover, health habits established in childhood may be sustained throughout life, more so than those acquired during any other period during the lifespan [5-7]. Thus, sun protection habits should begin early in life, be taught as part of routine preventive health care and in school settings, but bolstered again in adolescent years when such habits are 
known to deteriorate [8,9]. Early communication and role modeling by caregivers and parents regarding the importance of sun protection is the most essential aspect of the development of childhood sun protection behavior [5-7].

Powerful evidence implicates environmental and genetic interactions in melanoma causation. The phenomenon of stratospheric ozone depletion (which allows increased ultraviolet (UV) radiation to reach the earth's surface), exacerbated the negative health effects caused by the public spending more time in the sun.[10] Case-control studies led the 1992 International Agency for Research in Cancer to conclude that "ultraviolet light causes melanoma and nonmelanoma skin cancer" [11]. All Americans are at risk, but skin cancer in general is a disease of Caucasians, who have disease rates manifold that of non-whites [2]. In addition, those with excessive sun exposure (particularly during the first 20 years) or a tendency to burn rather than tan when exposed to sunlight are also at increased risk $[12,13]$. Further, patterns of sun exposure seem to be important in the development of these cancers. Intermittent sun exposure received during childhood and adolescence appears to be particularly important [12,13]. Moreover, children spend an estimated 2.5 to 3 hours outdoors each day; part of that time is during recess when they have a greater opportunity for midday sun exposure [14].

Public health advisories now recommend routine practice of sun protection behaviors, including limiting sun exposure, using sunscreens and protective clothing, minimizing sunburns, avoiding tanning beds, starting from childhood, and wearing sunglasses to prevent eye damage [15-17].

The SunWise School Program, developed by the United States Environmental Protection Agency (EPA), is the first national environmental and health education program for sun safety of children in elementary and middle schools [18]. SunWise's overall goal is to provide sun protection education to at least $20 \%$ of the nation's schools (grades K-8) by 2005 in order to ultimately reduce the incidence and effects of skin cancer and other UV-related health problems. Program features are designed to raise children's awareness of stratospheric ozone depletion, foster awareness of the need to protect one's skin and eyes from excessive sun exposure, teach simple sun protection steps, and deliver accurate, timely, and useful UV data directly to schools and communities for use in day-to-day decisions regarding personal sun safety. Recently, SunWise has expanded to alternative venues such as soccer programs and science and children's museums.

The purpose of this article is to present the results of SunWise's effects on students' knowledge, attitudes, and prac- tices and to report faculty (teacher or nurse) responses to the SunWise program.

\section{Methods}

All public and private elementary and middle schools in the United States are eligible to participate in the SunWise School Program. Schools are recruited by distributing information via conferences of various teacher and nurse organizations, meetings of skin cancer interest groups, newsletters, publications, the Internet, and referrals from partner organizations, such as the American Cancer Society and the SHADE Foundation (Arizona). Single classrooms, multiple classrooms, schools, or entire school districts were are eligible. All school faculty, including school nurses and classroom teachers, are recruited and eligible to participate.

The cross-curricular, standards-based classroom lessons were contained in an activity guide and later expanded in the SunWise Tool Kit. An expert panel of educators, curriculum specialists, and skin cancer researchers reviewed the lessons. Educational standards were established by governing bodies for each content area (e.g. - science standards were developed by the National Science Teachers Association, math standards by the National Council of Teachers of Mathematics) in order to have a consistent baseline of knowledge that students must have to progress from one grade tothe next. Lessons focus on three key areas: 1) the effects of UV radiation, 2) risk factors for overexposure, and 3) sun-protection habits. Each lesson consists of a variety of developmentally-appropriate activities meeting prescribed educational standards that combines education about sun protection and the environment with other aspects of student's regular learning in sciences, social studies, health, and mathematics. The expectation is that at least one or two hours will be spent on the activities.

There are at least 30 activities for faculty to choose from, ranging from lessons on ozone depletion to one on the testing of different sunscreens using a UV-sensitive Frisbee (included in Kit) (Figure 1).

Other activities are supplemented by the SunWise website, which offers schools the opportunity to check for the UV Index, report, chart, and compare UV measurements, and play educational games. Educators can similarly test the effectiveness of UV-blocking sunglasses.

To further encourage active participation in the program, SunWise launched an awards program in spring 2003 (Figure 2 ). The program was designed to officially recognize elementary and middle school educators and administrators who have shown an exemplary commitment to sun safety education. 
Step 1) Students place plastic wrap over the Frisbee

Step 2) Apply small circles of different levels of sunscreen on its surface

Step 3) Once the Frisbee is exposed to UV radiation, the undisturbed areas will change color, whereas the areas covered with sunscreen of SPF $15+$ will not, thus showing the students the effectiveness of sunscreen.

\section{Figure I}

Helios Awards for their work changing school policy, involving parents and the community, erecting shade structures on school playgrounds, and/or allowing sunscreen to be worn in school. The three recipients are Merryhill School in Davis, California, Bryon A. Barry Elementary in Phoenix, Arizona, and the Center for Creative Learning in St Louis, Missouri.

The Shining Star Award is given to schools who are implementing SunWise in an exemplary way: by reaching a large number of students: reporting UV data to EPA's web site: sponsoring poster contests; or developing curriculum. The 2003 Shining Star schools are Larson Middle School in Troy, Michigan; North Catholic High School in Pittsburgh, Pennsylvania; Sacred Heart in Louisville, Kentucky; Harrington Elementary in Denver, Colorado; Geneva Elementary School in Bellingham, Washington; George School in Westwood, New Jersey; Charlotte A. Dunning Elementary in Framingham, Massachusetts; Marin County Office of Education in San Rafael, California; San Simon School in San Simon, Arizona; Gus Garcia Middle School in San Antonio, Texas; and Goddard Middle School in Glendora, California.

\section{Figure 2}

SunWise School Awards 


\section{Evaluation}

Pretests and posttests in schools receiving SunWise program

The effect of classroom lessons on students' knowledge, attitudes, practices, and intended practice was evaluated using identical, self-administered pretest surveys distributed in September-March (autumn-spring) and posttests distributed immediately after teaching the SunWise educational program (generally May-June) (spring-summer).

The evaluation of the SunWise School Program was approved by the Boston Medical Center Institutional Review Board, which did not request parental consent or child assent since there were no personal identifiers on the survey form and the purpose of the evaluation was to track SunWise teaching. Surveys were collected and individually analyzed each year from 1999-2002 and no students or teachers were surveyed more than once. The number of schools from which the sample was drawn as of April of each of the school years was 25 in 1999, 130 in 2000, and 300 in 2001, and 3450 in 2002. From this roster of 3905 schools, using an alphabetical listing of all of the schools, we randomly chose 1 out of every 25 schools to participate in the survey process.

All schools agreeing to participate in the SunWise School Program must register at the SunWise website http:// www.epa.gov/sunwise. Teachers or nurses enrolling in the program include the address and state, as well as the grade level and the number of students in the school.

\section{Testing in schools receiving SunWise (experimental) and not} receiving SunWise (controls)

In the year 2000, all 9 elementary schools in Framingham, MA served as controls ( $\mathrm{n}=1,285$ students) and provided no education during spring months. School nurses conducted pretests (November) and posttests with $4^{\text {th }}$ and $5^{\text {th }}$ grade children in June. Student responses in the control schools were compared with the nationwide profile of children in similar grades receiving SunWise education in the spring of 2000 .

Surveys conducted by school nurses in two separate academic years Compared with responses from the earlier academic year, we sought to determine whether SunWise teaching would lead to maintenance of new knowledge and healthy attitudes, and if there would be any resultant changes in sun protection practices or sunburning rates. Therefore, since school nurses were more likely than classroom teachers to follow the same children in successive school years, in 11 schools, the nurses conducted 3 surveys-the pretest, the routine follow-up in the spring and a second follow-up survey in the following fall as the children had progressed to the next grade.

\section{Teacher surveys}

Separate teacher surveys were mailed to an additional 600 schools and 320 teachers responded (53\%). Teachers were asked to: rate their overall satisfaction with the program; describe infrastructure enhancements such as new school wide policies; report on change in their own personal sun protection behaviors; and note their receptiveness to: new curriculum on the safety of tanning beds.

\section{Measures and Scales}

The student survey was derived from other instruments, reviewed and edited by educational and child development experts, pilot tested by 10 children ages 6-7 for readability and length, and time tested to ensure completion within 5-7 minutes. The instrument included questions on demographics (age, sex, hair color); knowledge (appropriate SPF for outdoor play, highest UV Index number corresponding with need for sun protection, need for hats and shirts outside), attitudes (tanning as good or healthy, whether suntan is good for the skin); practices (sunscreen use and parts of the body covered with sunscreen, and use of hats, long-sleeved shirts, and sunglasses), and intended practices (sunscreen use and playing in shade for the upcoming summer). A single question asked children to report the number of sunburns experienced the previous summer. Students were asked, "when I'm outside in the sun during the summer, I wear sunscreen, hats, long-sleeved shirt, and sunglasses," and given the choices of all of the time, sometimes, and never.

For purposes of this analysis, the use of sunscreen, hat, and sunglasses was considered routine, if practiced all of the time, and use of long-sleeved shirts as routine, if practiced always or sometimes. Scales differed since earlier studies indicated that long-sleeve shirt use was far less commonly practiced than sunscreen [6]. Intended practices as a key outcome measure was chosen since much of the teaching occurred in the early spring and there was little opportunity for children to immediately change their sun protection practices.

\section{Data analysis}

Since the surveys were anonymous, it was not possible to link individual students' answers from both surveys. Therefore, the measure of the effect of the program is the difference between the pretest and the posttest in the percentage of students providing specific responses rather than the change in individual students' responses. Ninetyfive per cent confidence intervals of the difference between pretest and posttest and p-values using the chisquare test for $2 \times 2$ contingency tables were calculated. In order to control for slight differences in the age distribution of students at pretest and posttest, we age-standardized all proportions using the overall student age distribution as the standard. Since there were only very 
Table I: SunWise School Education Program - Evaluation of Student Responses, 1999-2002

\begin{tabular}{|c|c|c|c|c|c|c|}
\hline & \multicolumn{3}{|c|}{ 5-9 years old } & \multicolumn{3}{|c|}{$10-12$ years old } \\
\hline & $\begin{array}{c}\text { \% Pre } \\
(n=1,984)\end{array}$ & $\begin{array}{c}\% \text { Post } \\
(n=1,567)\end{array}$ & \% Diff & $\begin{array}{r}\% \text { Pre } \\
(n=3, \mid 47)\end{array}$ & $\begin{array}{r}\% \text { Post } \\
(n=2,972)\end{array}$ & \% Diff \\
\hline \multicolumn{7}{|l|}{ Knowledge } \\
\hline Wearing hat \& shirt are ways to protect one from the sun & $61.2 \%$ & $78.7 \%$ & $17.4 \%$ & $59.1 \%$ & $71.9 \%$ & $12.8 \%$ \\
\hline The right number SPF to use & $39.9 \%$ & $76.5 \%$ & $36.6 \%$ & $56.1 \%$ & $72.2 \%$ & $16.1 \%$ \\
\hline Sun protection and UV Index & $25.9 \%$ & $56.3 \%$ & $30.4 \%$ & $28.1 \%$ & $55.3 \%$ & $27.2 \%$ \\
\hline \multicolumn{7}{|l|}{ Attitudes } \\
\hline Suntan is good for my skin & $32.5 \%$ & $26.7 \%$ & $-5.8 \%$ & $23.6 \%$ & $18.0 \%$ & $-5.6 \%$ \\
\hline People look healthier with a tan & $36.8 \%$ & $26.9 \%$ & $-9.9 \%$ & $41.2 \%$ & $41.1 \%$ & $*-0.1 \%$ \\
\hline \multicolumn{7}{|l|}{ Practices } \\
\hline Wear sunscreen & $35.6 \%$ & $37.9 \%$ & $* 2.3 \%$ & $20.6 \%$ & $21.1 \%$ & $* 0.5 \%$ \\
\hline Wear hats & $17.2 \%$ & $21.4 \%$ & $4.2 \%$ & $13.9 \%$ & $16.3 \%$ & $2.4 \%$ \\
\hline Wear long-sleeved shirt & $26.6 \%$ & $32.2 \%$ & $5.6 \%$ & $18.1 \%$ & $20.9 \%$ & $2.7 \%$ \\
\hline Wear sunglasses & $25.4 \%$ & $29.5 \%$ & $4.1 \%$ & $19.9 \%$ & $21.1 \%$ & $* 1.2 \%$ \\
\hline \multicolumn{7}{|l|}{ Intended Practices } \\
\hline Do you think you will put on sunscreen this summer & $69.2 \%$ & $74.1 \%$ & $4.9 \%$ & $54.9 \%$ & $57.9 \%$ & $3.0 \%$ \\
\hline I will try to play in the shade instead of the sun & $77.6 \%$ & $83.5 \%$ & $5.9 \%$ & $64.0 \%$ & $64.6 \%$ & $* 0.5 \%$ \\
\hline
\end{tabular}

* Difference is not statistically significant using Z test (\% Diff / Pooled variance).

minor differences between the crude and age-adjusted results, we chose to present the crude results only.

The effects of the intervention were evaluated by adjusting for baseline difference (pre-experimental versus precontrol schools). Z-tests on $P_{\text {effect }}$ for statistical significance were performed.

\section{Results}

Of the 3905 schools registered as of April 2002, we chose 156 to participate in the survey process. Of these, 102 schools (65\%) completed pretests and posttests. A total of 5,625 pretests and 5,028 posttests were completed. There were no differences in geographic location or size of the school between all 3905 schools, the 156 schools invited to participate in the survey evaluation, and the 102 schools completing pretests and posttests. The majority of schools were public schools. An average of two classrooms per school (55 children per school) participated in the survey process.

Respondents were between the ages of 5 and 15, with 35\% of the children between the ages of 5-9 and 56\% of children between the ages of 10 and 12 . Only $9 \%$ of respondents were 13 years of age and above. School nurses led the programs in 29 of the 102 schools $(28 \%)$ and teachers conducted the program in the remaining $72 \%$ of schools. In separate surveys, nearly $90 \%$ of nurses and teachers reported that the lessons took between one and two hours to implement.
At baseline, 61\% of children reported that they had received a sunburn during the previous summer, with sunburn rates of 59\% in the youngest children (ages 5-9) and $63 \%$ in the children in the middle and oldest age group.

\section{Pretests and posttests in schools receiving SunWise program (Experimental schools) Knowledge}

Marked improvement was noted for all three knowledge variables (Table 1 and 2). Identifying that wearing a hat and shirt outside were ways to keep the skin safe from the sun improved overall from $60 \%$ to $74 \%$ ( $\mathrm{p}<0.001$ ) with sharpest changes among the youngest children. At pretest, $52 \%$ of children were aware that SPF 15 was the minimal number needed for sun protection, 35\% stated that they did not know, and 13\% identified less than SPF 15. At posttest, $77 \%$ indicated SPF 15 was the minimal number and the proportion of children who said they did not know this decreased to $16 \%(\mathrm{p}<0.001)$. Improvement was most striking for the youngest children, who began with the lowest knowledge base $(p<0.001)$. Awareness of the number from the UV Index that best correlated with the most optimal sun protection also improved overall from $29 \%$ to $57 \%(\mathrm{p}<0.001)$.

\section{Attitudes}

At pretest, the proportion of children stating that people look healthier with a suntan differed slightly for younger and older children. At posttest, the youngest children were most likely to report a change in attitudes (37\% to $27 \%$, p $<0.001$ ) (Table 1). Attitude changes were most prominent in the youngest age group, although some changes were 
Table 2: Evaluation of responses

\begin{tabular}{|c|c|c|c|c|c|c|}
\hline & \multicolumn{3}{|c|}{$13-15$ years old } & \multicolumn{3}{|c|}{ All persons (5- 15 years) } \\
\hline & $\%$ Pre $(n=494)$ & $\%$ Pre $(n=5,625)$ & $\%$ Post $(n=5,028)$ & $\%$ Diff & $\%$ Post $(n=47 I)$ & $\%$ Diff \\
\hline \multicolumn{7}{|l|}{ Knowledge } \\
\hline $\begin{array}{l}\text { Wearing hat \& shirt are ways to protect } \\
\text { one from the sun }\end{array}$ & $63.2 \%$ & $60.2 \%$ & $74.4 \%$ & $14.2 \%$ & $79.0 \%$ & $15.8 \%$ \\
\hline The right number SPF to use & $71.7 \%$ & $51.7 \%$ & $77.4 \%$ & $25.7 \%$ & $85.5 \%$ & $13.8 \%$ \\
\hline Sun protection and UV Index & $43.1 \%$ & $28.6 \%$ & $57.0 \%$ & $28.4 \%$ & $67.0 \%$ & $23.9 \%$ \\
\hline \multicolumn{7}{|l|}{ Attitudes } \\
\hline Suntan is good for my skin & $23.7 \%$ & $26.8 \%$ & $20.1 \%$ & $-6.7 \%$ & $20.5 \%$ & $*-3.2 \%$ \\
\hline People look healthier with a tan & $56.3 \%$ & $41.1 \%$ & $37.9 \%$ & $-3.1 \%$ & $56.3 \%$ & $* 0.0 \%$ \\
\hline \multicolumn{7}{|l|}{ Practices } \\
\hline Wear sunscreen & $10.4 \%$ & $25.0 \%$ & $25.2 \%$ & $* 0.2 \%$ & $9.8 \%$ & $*_{-0.6 \%}$ \\
\hline Wear hats & $14.3 \%$ & $15.2 \%$ & $17.5 \%$ & $2.3 \%$ & $12.7 \%$ & $*-1.7 \%$ \\
\hline Wear long-sleeved shirt & $13.3 \%$ & $16.4 \%$ & $24.5 \%$ & $8.1 \%$ & $22.9 \%$ & $9.6 \%$ \\
\hline Wear sunglasses & $20.6 \%$ & $21.8 \%$ & $23.5 \%$ & $1.6 \%$ & $19.5 \%$ & $*_{-1.2 \%}$ \\
\hline \multicolumn{7}{|l|}{ Intended Practices } \\
\hline $\begin{array}{l}\text { Do you think you will put on sunscreen } \\
\text { this summer }\end{array}$ & $36.4 \%$ & $58.3 \%$ & $60.9 \%$ & $2.6 \%$ & $38.5 \%$ & $* 2.1 \%$ \\
\hline $\begin{array}{l}\text { I will try to play in the shade instead of } \\
\text { the sun }\end{array}$ & $51.2 \%$ & $67.7 \%$ & $74.9 \%$ & $7.2 \%$ & $60.1 \%$ & $8.9 \%$ \\
\hline
\end{tabular}

made in children ages $10-12$. At baseline, $27 \%$ of children reported that they thought suntans were good for their skin compared with $20 \%$ at posttest $(\mathrm{p}<0.001)$, with a change in this belief least pronounced for oldest children (Table 1).

\section{Practice}

Overall, there were few changes in student's practice, although use of long-sleeved shirts showed some improvement at post-test. Sunscreen (25\%), long-sleeved shirts (25\%), sunglasses $(24 \%)$, and hats $(18 \%)$ were used sporadically with little change at posttest (Table 1). "All the time" use of sunscreen decreased by age, from $38 \%$ at ages $5-9$ to $21 \%$ at ages $10-12$ to $10 \%$ at ages $13-15$ (p < $0.001)$.

\section{Intended practices}

Overall, intentions to play in the shade increased from $68 \%$ to $75 \%$ from pretest to posttest $(\mathrm{p}=0.001$ ) with the smallest differences noted in children ages 10-12. Intentions to use sunscreen improved slightly from 58\% to $67 \%$ with few differences between younger and older children.

\section{Pretests and posttests in schools receiving SunWise program (Experimental schools) versus control school district}

There were no baseline differences in age, sex or frequency of sunburns between students in SunWise and Framingham control schools, although children in experimental schools were more likely to have light hair color. When controlling for hair color, no baseline differences were found between children in experimental and control schools on two of the three knowledge variables.

During the school year, the $1,2854^{\text {th }}$ and $5^{\text {th }}$ graders (mean age, 10) in control schools showed no improvement in knowledge or beliefs about tanning, and reported fewer intentions to play in the shade from pre-test to posttest. Overall, changes in knowledge, attitudes, and intentions were more likely in experimental schools than control schools. In particular, intentions to play in the shade improved by $5 \%$ in the experimental schools and dropped $8 \%$ in the control schools $(\mathrm{p}<0.05)$. Similarly, the attitude that people look healthier with a tan dropped in experimental schools, but rose in control schools $(\mathrm{p}<$ $0.05)$.

\section{Surveys conducted by school nurses in two separate academic years}

School nurses at 11 schools in six states surveyed the same children, first during the 2000-01(March-April) school year and again in the 2001-02 (October-November) school years. Among the 477 children (ages 5-13) completing three surveys, gains in knowledge and attitudes were maintained, but sunburning rates were lower in the most recent summer (55\% in summer 2001 compared with $66 \%$ for the summer, 2000 ( $p<0.05$ ). There were few differences in practices between the two periods although intentions to play in the shade increased from the earlier to the later period. 


\section{Teacher assessments}

Of the 320 teachers completing assessments, 28\% organized schoolwide activities and $12 \%$ changed sun protection policies. More than $90 \%$ rated teacher and student satisfaction to be high to very high. More than threefourths of teachers stated that they positively changed their sun protection practices as a result of the teaching. More than $90 \%$ expressed interest in continuing their participation in SunWise for upcoming years and showed willingness to share their materials with another faculty member. Teachers were very receptive to the following new educational programs, helping parents learn about sun protection $(70 \%)$, children resist tanning (64\%), and to create openness to new education on tanning beds (51\%), although the latter number was higher for teachers of older children. SunWise lessons were taught primarily in science $(59 \%)$, health (51\%), math $(28 \%)$, physical education (14\%), and Social Studies (8\%) (more than one class allowed).

We attempted to account for two biases common with studies of this type. First, we were concerned that teachers and nurses in 1999 would be more enthusiastic about the program than teachers in the latter period (2002), thus resulting in higher change scores. However, we did not find any noticeable differences in knowledge or attitudes between students completing surveys in 1999 and 2002. For example, $41 \%$ of $10-12$ year olds in 2000 stated that people look healthier with a tan compared with $44 \%$ in 2002.

\section{Discussion}

The Environmental Protection Agency's SunWise School Program, consisting of an estimated 1-2 hours of teaching per year, resulted in substantial improvements in children's knowledge, and modest changes in children's perception of the healthiness of a tan and for their intentions to play in the shade. More innovative study designs will be necessary to monitor changes in practice among students exposed to SunWise education. More broadly, sun protection education in outdoor recreational settings must complement initiatives such as the SunWise program.

Strikingly, $61 \%$ of children reported having at least one sunburn the previous summer, with few differences between youngest and oldest children. Part of the explanation of high sunburning rates for these children can be found in their rates of sun protection that do not exceed $25 \%$.

Schools are important settings for sun protection education as children spend time outdoors during peak sun intensity hours for recess, lunch, physical education, and after-school activities [14,19]. Ideally, lessons from the classroom can be immediately put into place on the schoolyard. School health programs are beset with nationwide budget cuts, increasing class sizes, and time limitations due to national standards for core reading and math skills. Therefore, teaching of new health curriculum must be effective, economical, and woven into the school lessons. This study has shown that brief sun protection teaching intertwined into the standard curriculum, with standardized but flexible lessons, can boost student knowledge and begin to have an effect on children's attitudes.

SunWise teaching is consistent with the Centers for Disease Control and Prevention's (CDC) recently developed guidelines for school programs to prevent skin cancer [19]. Recommendations included policies, creation of physical, social, and organizational environments that facilitate protection from UV rays; education of young persons; professional development of staff; involvement of families; health services; and program evaluation [19].

A recent national survey of 412 US elementary school principals found that only $3 \%$ of schools had a policy with rules or recommendations for students, teachers, staff or parents designed to improve sun protection. No differences were found between sunny and cooler states [14]. Many children and school staff were outside, unprotected from the sun. Many school principals were willing to develop such policies but are unaware of skin cancer as a health problem or the role that their schools could play in preventing adverse exposures.

In addition to increasing student knowledge and awareness, school faculty can band together with community groups and parent-teacher organizations to develop sun protection policies within schools, including: improving shading on the playground, providing sunscreen reminder notes to parents before outdoor school field trips, suggesting tips for better protection during recess, and increasing availability of sunscreen in the nurse's office. The SunWise Tool Kit contains resources for policy implementation.

\section{Limitations}

There are a number of limitations to this study. First, school nurses and teachers volunteering to participate in the SunWise program may have strong personal interests (for example, personal or family history of skin cancer that may have motivated them to teach the program). We did not include questions on school faculty's perceptions of their own risk. We attempted to account for bias resulting from self-selection by comparing the earliest participating schools with later ones and found no differences in baseline prevention rates or change scores resulting from the intervention. Second, we also compared sunburning rates and sun protection use among children in this study 
with studies based on comparable populations [6,20-22]. The fact that sun protection rates in schools participating in SunWise compare to population-based studies does not rule out the possibility of unique 'sun-protected' SunWise schools or children. Third, the positive changes in knowledge and attitudes that occurred during the 4-5 months between pretests and posttests may have occurred elsewhere. To examine the potential of changes that may have occurred apart from school curriculum, results in experimental schools were compared with one control school district, where no differences were observed. Although comparisons were made between $4^{\text {th }}$ and $5^{\text {th }}$ grade children in SunWise and control schools, the comparison is from only one school district limiting the variation in the observed measures. Fourth, it is difficult to measure real change in sun protection practices over such a short time span, particularly among children in cooler climates who may not have the opportunity to practice newly-learned skills right after teaching in May. Therefore, we chose to measure students' intention to change as well as actual changes in their practice. In other studies, intent has been found to be a good predictor of actual behavior [23], although intentions in this study weakly predict real practice of sunscreen use. Finally, without objective measures of children's practice, we must rely on their selfreports, which are susceptible to memory errors and social desirability tendencies. Using objective measures such as badges to monitor actual exposure is likely not feasible in the school setting but has potential in some studies.

\section{Conclusions}

Schools face an increasingly wide array of educational and social demands. They are likely to place higher priority on other health-related issues such as bullying, teasing, substance abuse, and nutrition than on sun safety. Thus, in general, skin cancer prevention and environmental awareness education must be taught within a limited time frame and be embedded in other subjects. School sun protection education will need to be bolstered by community-wide efforts, revised policies at outdoor recreation sites, and outreach to parents and other caregivers. School-based education is essential, but comprises only one of the multiple 'hits' and reinforcements that children need to influence their sun protection behaviors. SunWise community education efforts currently underway include those with Major League Soccer and for the development of exhibits at children's and science museums.

Evaluation of students receiving this national educational program indicates that important knowledge can be acquired, attitudes regarding the healthiness of a tan can be modified, and intentions to change behavior can be promoted. Further work is needed to advance a 'schools and pools' approach. Combining the two would likely yield stronger behavioral effects.

\section{Competing Interests}

None declared.

\section{Authors' contributions}

ACG directed the evaluation and project design. LR, KK, and PS supervised and directed the SunWise program and assisted with manuscript review. ZZ was responsible for data management and analysis.

\section{Acknowledgements}

This study was performed under contract from the Environmental Protection Agency's SunWise School Program 3W-36I7-NTEX

We would like to acknowledge Drusilla Hufford, Kevin Rosseel, Maura Cantor, and Kathryn Parker from the Environmental Protection Agency for their unending encouragement of the program. We also thank the teachers and school nurses who participated in the evaluation of the SunWise program.

\section{References}

I. Jemal A, Thomas A, Murray T and Thun M: Cancer statistics, 2002. Ca: A Cancer Journal for Clinicians 2002, 52:23-47.

2. Ries LAG, Eisner MP, Kosary CL, Hankey BF, Miller BA, Clegg L, Mariotto A, Fay MP, Feuer E], Edwards BK and eds: SEER Cancer Statistics Review, 1975-2000. National Cancer Institute 2003 [http:// seer.cancer.gov/csr/l975 2000].

3. Howe HL, Wingo PA, Thun MT, Ries LA, Rosenberg HM, Feigal EG and Edwards BK: Annual report to the nation on the status of cancer (1973 through 1998), featuring cancers with increasing trends. I Natl Cancer Instit 200I, 93:824-842.

4. Hill D, White V, Marks R, Theobald T, Borland R and Roy C: Melanoma prevention: Behavioral and nonbehavioral factors in sunburn among an Australian urban population. Prev Med 1992, 2 1:654-669.

5. Marks R: Skin cancer - childhood protection affords lifetime protection. Med J Aust 1987, 147:475-476.

6. O'Riordan D, Geller AC, Brooks DR, Zhang Z and Miller DR: Sunburn reduction through parental role modeling and sunscreen vigilance: A national survey of 651 parents. J Pediatr 2003, I42:67-72.

7. Buller DB, Callister MA and Reichert T: Skin cancer prevention by parents of young children: Health information sources, skin cancer knowledge, and sun-protection practices. Oncol Nurs Forum 1995, 22:1559-1566.

8. Schofield PE, Freeman JL, Dixon HG, Borland R and Hill DJ: Trends in sun protection behaviour among Australian young adults. Australian and New Zealand Journal of Public Health 2001, 25:62-5.

9. Kelder SH, Perry $\mathrm{CL}$ and Klepp $\mathrm{KI}$ et al.: Longitudinal tracking of adolescent smoking, physical activity, and food choice behaviors. Am J Pub Health 1994, 84: I I I I-6.

10. Scotto J, Cotton G, Urbach F, Berger D and Fears T: Biologically effective ultraviolet radiation: surface measurements in the United States, 1974 to 1985. Science 1988, 239(484I Pt I):762-4.

II. International Agency for Research on Cancer, World Health Organization: Solar and ultraviolet radiation. Geneva: International Agency for Research on Cancer Volume 55. Geneva; 1992:336.

12. Gilchrest BA, Eller MS, Geller AC and Yaar M: The pathogenesis of melanoma induced by ultraviolet radiation. $N$ Engl J Med 1999, 340:|34|-|348.

13. Weinstock MA, Colditz GA, Willett WC, Stampfer MJ, Bronstein BR, Mihm MC Jr and Speizer FE: Nonfamilial cutaneous melanoma incidence in women associated with sun exposure before 20 years of age. Pediatrics 1989, 84:199-204.

14. Buller D, Geller AC, Cantor M, Buller MK, Rosseel K, Hufford D, Benjes $L$ and Lew RA: Sun protection policies in US elementary schools. Arch Dermatol 2002, 138:77I-774.

15. Emmons KM and Colditz GA: Preventing excess sun exposure: it is time for a national policy (editorial comment). J Natl Cancer Instit 1999, 91:1269-1270. 
16. Jorgensen CM, Wayman J, Green C and Gelb CA: Using health communication for primary prevention of skin cancer: CDC's Choose Your Cover Campaign. J Womens Health Gend Based Med 2000, 9:47I-5.

17. Lim HW and Cooper K: The health impact of solar radiation and prevention strategies: Report of the Environment Council, American Academy of Dermatology. J Am Acad Dermatol 1999, 41:81-99.

18. Geller AC, Cantor M, Kenausis K, Rosseel K, Rutsch L, Brooks D, Zhang Z, Miller DR and Demierre MF: The Environmental Protection Agency's National SunWise School Program: 19992000. Am Acad Dermatol 2002, 46:683-9.

19. Centers for Disease Control and Prevention: Guidelines for school programs to prevent skin cancer. MMWR Morbidity and Mortality Weekly Report 2002, 5 I: I-I9.

20. Robinson JK, Rademaker AW, Sylvester JA and Cook B: Summer sun exposure knowledge, attitudes and behaviors of Midwest adolescents. Prev Med 1997, 26:364-372.

21. Alberg AJ, Herbst RM and Genkinger JM et al:: Knowledge, attitudes, and behaviors toward skin cancer in Maryland youth. J Adolescent Health 2002, 3 I:372-7.

22. Coogan PF, Geller AC, Adams M, Benjes L and Koh HK: Sun protection practices in pre-adolescents and adolescents: $A$ school-based survey of almost 25,000 Connecticut school children. J Am Acad Dermatol 200I, 44:5I 2-9.

23. Arthey $S$ and Clarke VA: Suntanning and sun protection: $\mathbf{A}$ review of the psychological literature. Soc Sci Med J 1995, 40:265-274.

\section{Pre-publication history}

The pre-publication history for this paper can be accessed here:

http://www.biomedcentral.com/content/backmatter/ 1476-069X-2-13-b1.pdf

Publish with Bio Med Central and every scientist can read your work free of charge

"BioMed Central will be the most significant development for disseminating the results of biomedical research in our lifetime. "

Sir Paul Nurse, Cancer Research UK

Your research papers will be:

- available free of charge to the entire biomedical community

- peer reviewed and published immediately upon acceptance

- cited in PubMed and archived on PubMed Central

- yours - you keep the copyright 